\title{
The concept of a methodology for assessment of programmes of measures in implementation of the Water Framework Directive 2000/60/EC
}

\author{
Tomasz Walczykiewicz, Ilona Biedroń \\ Institute of Meteorology and Water Management - National Research Institute, Branch in Kraków, Division of Water \\ Management, Borowego Street 14,30-215 Kraków, Poland, e-mail: tomasz.walczykiewicz@imgw.pl, ilona.biedron@ \\ imgw.pl
}

\begin{abstract}
This article presents the concept of the methodology for assessing the implementation of programmes of measures adopted in the State Water and Environmental Programme, and, in consequence, in the framework of the first water management plans for river basin districts in Poland, as approved by the Council of Ministers on $22^{\text {nd }} \mathrm{Fe}-$ bruary, 2011, and published in the official journals.

The scope of work in the methodology concept primarily concerns two basic analyses: assessment of the accomplishment of programmes of measures with regard to the degree of their accomplishment, and assessment of the effectiveness of scheduled programmes of measures. The level of accomplishment should be understood as the quantitative status of progress of particular measures, whereas effectiveness means their direct or indirect impact on the achievement of environmental goals of the Water Framework Directive.

For this purpose, for some of the measures databases and reports existing in institutions responsible for the performance of measures indicated in the SWEP were used. For the rest of the measures, the survey method was used. For the purpose of the surveying process, the preparation of appropriate matrixes with measures marked for institutions, and also of email address databases, were proposed. Also, identifiers serving to link answers with specific areas on maps that trace measures were proposed.

The present and forecast situation concerning reporting in the scope of the WFD and other tasks connected with it in the field of environmental protection leads to the conclusion that the coordination of reporting at the state level and the improvement of the flow of information between interested institutions is necessary.
\end{abstract}

Keywords: programmes of measures, Water Framework Directive 2000/60/EC, the State Water and Environment Programme (SWEP)

Submitted 5 March 2014, revised 21 November 2014, accepted 25 Novemer 2014

\section{Introduction}

This article presents the concept of methodology to assess the implementation of programmes of measures adopted in the State Water and Environmental Programme (SWEP 2010), and, in consequence, in the framework of the first water management plans for river basin districts in Poland, as approved by the Council of Ministers on $22^{\text {nd }}$ February, 2011, and published in the official journals. Programmes of measures included in the SWEP adopted in Poland in the process of the elaboration of water management plans (WMP) for river basin districts (Fig. 1) have primary importance for the strategy for protecting groundwaters and surface waters from contamination and for achieving their good status, according to the requirements of the Water Framework Directive 2000/60/EC (WFD). Programmes of measures should take into account the analyses undertaken on the basis of Article 5 of the
Directive, and also the outcomes of monitoring established under Article 8 of the WFD.

Water management plans contain a synthetic presentation of programmes of measures. Verification of programmes of measures in the first half of the planning cycle on the level of river basin districts concerns the implementation (assessment of progress of implementation) of all measures included in the report submitted to EC in year 2010. For the country's internal purposes an attempt to assess the implemented programmes' effectiveness was also made. In this process it is very important to include the scientific and research progress, as well as to include the participation of local communities, representatives of sectors of industry and agriculture and of non-governmental organizations in the verification of the plans.

Each programme of measures must contain basic measures and, where necessary, also some supplementary ones. Basic measures can be divided into measures regulated by 


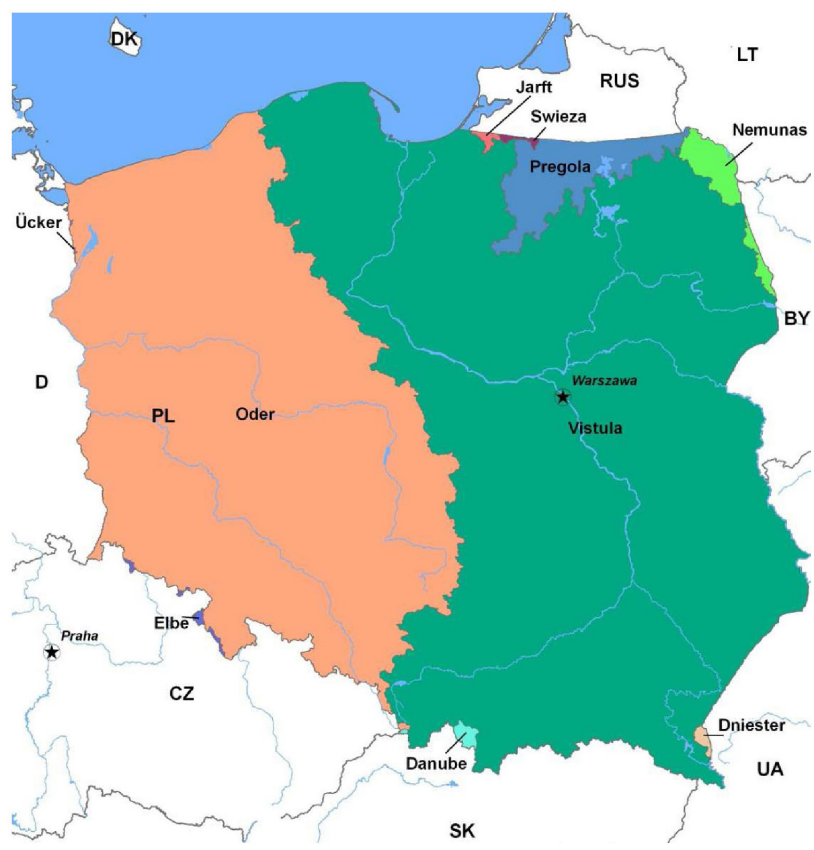

Fig. 1 River basin districts in Poland; source: own elaboration

other directives (among others, those mentioned in Annex VI, part A of the WFD) and the measures introduced by the WFD itself (Article 11, Item 3, Points (b) to (1)).

A general non-exhaustive list of measures is included in Annex VI to the WFD in part B.

According to the wording of the SWEP, the arrangements set out therein should be transferred to other documents at the national and regional level, by including their provisions in strategies, operational and development programmes, studies of conditions and directions of spatial development, spatial development plans and also in thematic plans and programmes connected directly or indirectly with water management. Such a situation, according to the SWEP authors, should enable the full implementation of measures planned for the particular water bodies.

The elaboration of the methodology concept of the assessment, together with the conducting of the assessment, was entrusted by the National Water Management Authority (NWMA) ${ }^{1}$ to the Institute of Meteorology and Water Management, National Research Institute (IMWM-NRI). The main author of this article was the leader of the team implementing the above mentioned Project, which was completed with the submission of a report to the European Commission in December 2012. In March 2012 the work on the concept of the methodology for conducting the assessment were completed. In the last stage, this methodology will be verified on the basis of the experiences of IMWM-NRI in relation to the collection of data for the

${ }^{1}$ The National Water Management Authority is a central governmental body responsible for water conservation, and especially for water management and water use (Elaboration of analysis the pressures and impact 2007) purposes of assessing the degree of measure implementation and evaluation of the effectiveness of measures.

\section{Basis for reporting resulting from the organisation of the WFD implementing process}

According to the European Commission all reports connected with WFD implementation are to serve to:

- assess the problems in the field of water management in particular countries,

- assess the planning process in each country,

- allow comparative analyses conducted by the European Commission,

- assist the planning of future works on the improvement of the status of water resources.

The guarantee of comparability, and of the ability to conduct cross-section assessment, are, according to the European Commission, ensured by the use of the special reporting questionnaires developed by a working group D ("Reporting"); they function at the Commission and were created in the framework of the Common Strategy for Water Framework Directive (CIS 2009).

In the context of the Common Implementation Strategy - CIS - a range of working groups were set up and common measures concerning the elaboration and verification of non- binding Guidelines were undertaken. Working groups are supervised by a strategic coordination group, which is subject directly to the European Union Water Directors and to the Commission (CIS 2009).

Within the Strategy, inter alia, documents detailing the methodological approach to the process of implementation (guidebooks - handbooks) were created; and activities to coordinate the WFD implementation are carried out - these include those in the scope of progress reporting systems in the individual Member States of the EU.

The characteristic feature of the reporting system proposed by the European Union is its dynamic character. It is emphasised that the key element for programmes of measure reporting is the status of body of waters. As a result, for those that have not reached a good status before the launch of the first water management plans $\left(22^{\text {nd }}\right.$ December 2009) a plan that will enable this by 2015 , or, when appropriate, in the next planning periods $(2021,2027)$ should be implemented.

A planning process in accordance with the WFD is a continuous process, carried out in six-year cycles. Between the particular editions of plans, the following take place: the evaluation of results and the introduction of changes, including those resulting from the identification of new data, and from the carrying out of further complementary analysis, as well as from the changes re- 
sulting from, inter alia, the improvement of water status and the verification of the division into uniform bodies of water. The planning during each stage takes advantage of the fullest data possible, and of available techniques and methodological solutions. It also includes the possibility of introducing changes resulting from the improvement in forms of data availability, and also the improvement of techniques, methodologies and research tools.

According to the schedule of WFD implementation, the first update of water management plans for the river basin districts (year 2015) should be preceded by the measures shown below (Act of Water Law 2001):

- Implementing a programme of measures (years 20092012);

- Putting programmes into practice (year 2012);

- Updating the analysis of river basin status (year 2013);

- Reviewing the programmes of measures and water management plans in a river basin district (years 2013 2014);

- Publishing an updated water management plan for the river basin district (year 2015).

The above mentioned working group D ("Reporting") has its regular meetings approximately twice a year. At the meeting in March 2012, the following position of the Commission, relevant to the process of assessment of programmes of measure implementation, was presented:

- individual Member States will receive correspondence from the Commission. On the basis of this it will be necessary to clarify problems and uncertainties arising from water management programmes for river basin districts and from adopted programmes of measures;

- any amendments and corrections concerning measures and water management plans will be included in the WISE system (The Water Information System for Europe) (WFD Reporting 2011) - this is the basis for making any further assessment by the EC;

- correspondence with Member States initiated by the Commission will seek to validate the conducted assessments.

\section{The scope of the adopted concept of evaluation} methodology for programmes of measures under the State Water and Environmental Programme

The scope of work in the methodology concept primarily concerns the two basic analyses:

- assessment of the accomplishment of programmes of measures with regard to the degree (status) of their accomplishment (implementation),

- assessment of effectiveness of scheduled programmes of measures.
The last stage of work will be the preparation of a report to the European Commission concerning the progress in the implementation of the planned programmes of measures in accordance with Art. 15 Item 3 of the WFD, and also the preparation of a report for the NWMA.

The level of accomplishment should be understood as the quantitative status of progress of particular measures, whereas effectiveness means their direct or indirect impact on the achievement of the environmental goals of the WFD. According to guidelines and handbooks accompanying the WFD and elaborated in the process of the Common WFD Implementation Strategy, the adopted sets of measures in the SWEP should be characterised by the highest level of effectiveness.

\section{Methodological foundations for the assessment of the level of implementation of measures}

Guidelines to the report 'Progress on the implementation of the Programmes of Measures' (version of $18^{\text {th }}$ May 2011) (ATKINS 2011), elaborated by the Commission and consulted in the working group "Reporting", are the methodological foundations for the assessment of the level of the implementation of measures.

According to the WFD and the above mentioned guidelines, the measures were divided into two groups:

- The first group - basic measures following from Art. 11.3(a) (eleven Directives listed in Annex VI part A).

In the case of these measures, the Commission does not expect specific information, as it is delivered in the reports from particular directives. The overall report (in the form of text of up to 2000 characters) should include a general estimation of the extent of their implementation, in particular in relation to their participation in achieving the goals of the WFD.

- The second group - basic measures Art. 11.3 from (b) to (1) and also supplementary measures.

The degree of the implementation of the activities from this group (implementation status predicted for $22^{\text {nd }}$ December 2012) will be evaluated through a quantitative factor, though in the division including the criteria related to the nature of a measure and its state of advancement:

- for non-investment activities:

o not started - it is not expected that operation will start by the end of year 2012 (a short explanation for why this is the case is required);

o on-going - the measure has been started and is in progress (explanation of possible delays);

o completed;

- for investment activities: 
o not started-administrative and technical procedures have not been started;

o in the planning phase - administrative procedures have been started but not completed;

o in the building phase - construction work has started, but has not been completed;

o completed - construction work has been completed, may now be in a start-up phase.

In the 2012 report, according to the guidelines (ATKINS 2011), information concerning the degree of implementation of all measures included in programmes from the 2010 report are to take the qualitative form. However, for key measures - those which have a decisive impact on achievement the WFD goals - Information is to be presented in the quantitative form. For measures repeated across the EU, appropriate quantitative indicators were proposed. At the same time it is permissible to introduce one's own indicators, however, they must be defined, a base unit and a base value must be provided, as must a value indicating progress in the implementation process.

The examples of indicators, proposed in the above mentioned guidelines for activities not resulting directly from the Directives listed in Annex VI to the WFD, part A, are given below. Measures concerning the reduction of pollutants from point sources:

- the equivalent number of inhabitants covered by the measure;

- the number of projects per water body or group of bodies of water the expected total cost of measures in euros.

Measures concerning the reduction of pollutants from area sources:

- area in $\mathrm{km}^{2}$ of arable land covered by the measures aimed at the reduction of pollution by biogenic compounds;

- area in $\mathrm{km}^{2}$ of arable land covered by the measures aimed at the reduction of pollution by pesticides;

- the number of projects per water body or group of bodies of water the expected total cost of measures in euros. Corrective measures for previously polluted sites (sediments, groundwaters, soil):

- the area in $\mathrm{km}^{2}$ of land covered by the measure;

- the number of sites covered by the measure;

- the expected total cost of measures in euros. Measures concerning hydromorphology of waters:

- the number of projects serving for river continuity per water body or group of bodies of water the length (in $\mathrm{km}$ ) of a riverin which hydromorphological conditions have been improved;

- the area (in $\mathrm{km}^{2}$ ) of a river basin district in which hydromorphological conditions have been improved;
- the number of projects serving the improvement of hydromorphological conditions;

- the number of projects serving the improvement of a flow regime (instream flow) including permits per water body or group of bodies of water the length of a river in $\mathrm{km}$, in which the flow regime has been improved;

- the expected total cost of measures in euros.

Technical measures concerning the amounts of water:

- area covered by projects for the improvement of irrigation effectiveness:

- the number of projects serving the improvement of irrigation effectiveness;

- the expected total cost of measures in euros.

- recovery of costs for water services:

- the actual and expected number of people covered by the principle of recovery of water services costs

- the actual and expected area in $\mathrm{km}^{2}$ covered by the principle of recovery of water services costs for households;

- the actual and expected number of industrial units covered by the principle of recovery of water services costs;

- the actual and expected area in $\mathrm{km}^{2}$ covered by the principle of recovery of water services costs for agriculture.

Other measures:

- the actual and expected number of agricultural holdings covered by the advisory service;

- the actual and expected agricultural area covered by the advisory service;

- the actual and expected number of safeguard zones of water intakes;

- the number of studies, and research and development projects;

- expected total cost in euros of research, studies, development projects;

- technical measures for the reduction of the emission of priority substances (number of permits, number of projects, cost);

- technical measures for the improvement of industrial waste-water collection outside of the IPPC directive (ATKINS 2011) (number of projects and their cost).

The analysis of the guidelines (ATKINS 2011) shows how detailed the available data and information must be in order to fulfil the requirements of the 2012 report to the Commission. In the case of operations reported for the SWEP, a similar approach was assumed in the concept, only in some cases it was simplified into two criteria related to the state of advancement ('not completed', 'completed'). In the case of measures arising from the Directives 
enumerated in Annex VI, part A, it is planned that the indicators from their reports will be used, or new ones will be introduced in consultation with the bodies responsible for their reporting.

\section{Methodological grounds for the assessment of the effectiveness of measures}

As mentioned in the introduction, the basic goal of the WFD is the achievement of a good ecological (for surface waters) or quantitative (for groundwaters) status/ potential, as well as a good chemical status, measured by the standardised quality elements. The values of these elements are determined on the basis of water monitoring, and their comparison with normative values allows for the ascertainment of whether or not a basic objective of the WFD has been reached and, possibly, which quality elements have an impact on the accomplishment of this objective. However, one should realise that the reaction time of the environment to a given measure - for example those concerning area pollution - may range from several to scores of years (related to the time pollution remains in the ground). In the case of some activities - such as educational ones - It is hard to determine which element of water quality they may have an indirect impact on, and in what time framethey will bring effects.

All measures undertaken together in a river basin that belongs to a section designated by the location of a monitoring point, and thus the measures for all water bodies within a given river basin, have an impact on the reaction of the environment. However, knowledge about which activities and in which water bodies they might have contributed, or may contribute, in the most significant way to the implementation of WFD objectives is important.

Therefore, the assessment of their effectiveness cannot be based on the results of water monitoring only, but must also include the degree to which measures are implemented, their character and also the reaction time of the environment. Only these comparative studies allow for the determining of whether, in the future, the performed measures will allow for the achievement of WFD objectives, and whether problems with achieving these objectives stem from insufficient progress or from ill-assorted measures in relation to existing pressure factors (a comparison with the outcomes of a pressure and impact analysis (Directive 2008/1/EC)). These analyses are the basis for the assessment of the grounds for discrepancies in planned programmes in relation to the assumed effects, as well the basis for setting the criteria that determine the necessity for additional measures.
In the methodology concept, the balanced river basins of regional water management authorities were proposed as the basic area units for the analysis of efficacy. ${ }^{2}$ The reference point will be the results of monitoring in year 2011 , or in cases where this data is not available, those from the previous years, compared with the normative values.

Due to the possibility of a direct (defined in quantitative or qualitative scale) transposition to a given quality element and expected response time of the environment, measures were assigned to the following groups:

- Quick environmental reaction with quantitative transposition (reduced load, decreased power consumption), or in a qualitative scale (great, medium, small impact) on the quality element - e.g. the activities related to point discharges, abstraction of water.

- Slow reaction of the environment with quantitative transposition, or in the qualitative scale in the transposition on a quality element - e.g. measures concerning area pollution or restoring river continuum.

- Inability to determine the direct impact on the quality component and reaction time, and therefore difficulty in determining efficacy (in some cases, possibly, in the qualitative scale - e.g. educational and informational activities, activities of general environmental character (afforestation, elaboration of local area development plans, including requirements and principles of environment protection).

\section{The concept of characteristics of measures to be evaluated}

The framework characteristic of measures included in the SWEP is a crucial element of the concept which regulates the process of assessment. Each measure, or group of measures, was described according to the following scheme:

- Name of measure or group of measures.

- A short description containing the measure classification according to the WFD, legal basis, remarks, comments.

- The existing forms of reporting related to the fact that the measure is included in the Directives, in Annex VI part A of the WFD, programmes elaborated from

${ }^{2}$ At the beginning of the nineties the real reorganisation of water management in Poland started. The Amendment of the Act on Water Law from 1990 authorised the Minister of the Environment, Natural Resources and Forestry to create organisational units that execute the tasks of managing waters from the hydrographic perspective. In 1991 seven regional water management authorities were created. On $18^{\text {th }}$ July 2001 the new Act on Water Law was enacted; it introduced water management that includes the division of the country into river basin districts and water regions. 
a country or voivodship perspective (e.g. a programme of increasing afforestation) or that the measure is the sole duty of an administrative unit (e.g. of a commune (gmina) or of an institution (e.g. Regional Inspectorate of Environment Protection, regional Water Management Authorities). The following were given: the frequency of preparing reports (e.g. to the European Commission), the mode of data gathering between reports and the mode of making statements between reports, as well as the form of reports, databases, availability of statements

- Indicators of the implementation of a measure.

- Indicators of the assessment of a measure's effectiveness.

- Monitoring that includes the form of collecting information (the manner of documentation), progress in implementing a measure and reporting its results to the units responsible for reporting on the measures.

- The proposed form of reporting of the implementation of measures that comprises the assessment of whether the existing reporting scheme, i.e. its scope and shape, is enough to calculate the factors, suggestion to introduce corrections into the existing reporting scheme, proposal of a new form of reporting (including e.g. survey questions aimed at, among others, communes as the units responsible for the implementation of measures).

- The control of measure implementation encompassing the existing forms of control (controlling unit, frequency of controls, reporting and availability of data, assessment of whether the existing form of control is enough and whether the President of the NWMA is authorised to limit the control to the assessment of the only the degree of measure implementation).

\section{Gathering of information for the assessment of the execution of programmes}

The assessment of the degree of the execution of planned measures requires the gathering of a range of information from institutions responsible for the performance (execution) of measures indicated in the SWEP. For this purpose, for some measures, the databases and reports existing in those institutions were used. For the rest of the measures, as agreed with NWMA, the survey method was used. Due to the predicted large amount of material to be gathered, other methods of obtaining data were discarded. For each such measure and for each institution responsible for its execution, surveying questions were elaborated.

A sample survey concerning the measure with SWEP code - DK.PR.1 is presented below:
DK.PR.1 The use of plant protection products admitted to trading.

SURVEY for The Ministry of Agriculture and Rural Development

\section{Questions asked:}

1. Have the provisions of the Council Directive of $15^{\text {th }}$ July 1991 concerning putting plant protection products into trading (91/414/EEC) been implemented into Polish law?

2. Is there a register maintained concerning plant protection products admitted to trading and usage?

3. Please specify the amount of plant protection products sales [kg] in Poland in year 2010.

4. Please specify the amount of plant protection products sales [kg] in Poland in year 2011.

5. Please provide information on the progress in implementing The Plant Protection Products Directive, particularly in relation to its participation in achieving the WFD objectives (general quantitative data, if available).

SURVEY for The Main Inspectorate of Plant Health and Seed Inspection

Questions asked:

1. Percentage share of irregularities in the overall number of controls carried out concerning trading and usage of plant protection products in years 2010 and 2011.

In the concept, apart from the questions directly concerning the elements that allow for the assessment of the degree of the implementation of the measure, general questions about the possible delays in the measure's implementation and the causes of any delays, the financial securing of the measure's implementation, and the sources of financing with particular reference to European funds were also proposed. These questions arise from the need to report the state of implementation to the European Commission, according to the guidelines presented above (ATKINS 2011).

Surveys were prepared for: offices of communes, offices of poviats, offices of voivodships, offices of marshalls, voivodeship inspectorates for environmental protection, regional directorates for environmental protection, voivodeship boards for drainage and water facilities, agricultural advisory centres, regional water management authorities, the state fire service at the central level, the state sanitary inspectorate at the central level, the main inspectorate of plant health and seed inspection at the central level, state forests at the central level and ministries of 
the environment, agriculture, infrastructure, and internal affairs.

For the purpose of the surveying process, the preparation of appropriate matrixes with measures marked for institutions, and also of email address databases were proposed. Also, identifiers serving to link answers with specific areas on maps that trace measures were proposed.

The concept of the distribution of the surveys and also of collecting answers via electronic means was based on www technology. The distribution of surveys via emails was envisaged, on the assumption that respondents will have access to individual links to Internet surveys. Such a method allowed for the gathering of data on the server.

It was assumed that the surveys for communes would be sent via electronic means to the general email address of the office. The source of address information was the address database of local government units in Poland, kept by the Department of Public Administration of the Ministry of Administration and Digitalisation (MAD). On the Ministry's website the contact information for poviat and voivodeship administrative units are also available.

\section{The concept of the preparation of administrative} areas layers, identifiers and email addresses of units responsible for the implementation of measures.

According to the reporting scheme (Fig. 2), for the purpose of the evaluation of the implementation of measures and their spatial localisation it was necessary to prepare the appropriate spatial GIS data of administrative units.

Due to the fact that the measures in the SWEP were ascribed to BSW, the survey was directed to all administrative units responsible for the implementation of measures that lie within particular bodies of water, as defined in the Programme. Ascribing measures to BSW causes problems connected with the analysis of a survey's outcomes, e.g.

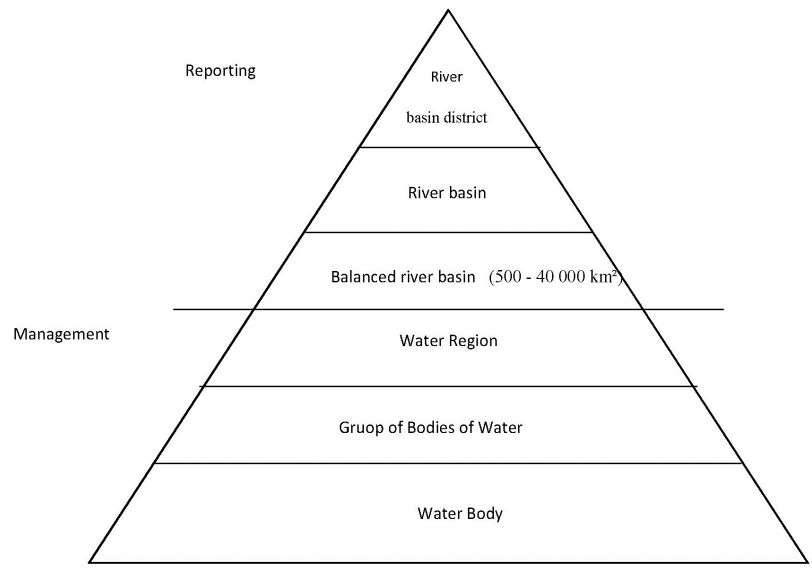

Fig. 2. Reporting scheme; source: own elaboration based on (ATKINS 2011) from communes belonging to more than one water body. Ultimately, information on the degree of measure implementation obtained from the administrative units responsible for their implementation will be transposed to group of bodies of water.

\section{The concept of a virtual server that operates the distribution and gathering of surveys}

The distribution of surveys and the gathering of responses to them were done automatically. This was possible thanks to a virtual server equipped with tools for handling the mail system and web pages with the content of surveys.

For this purpose a script of bash shell language was prepared. Its task was to send emails automatically to all institutions with the appropriate attachments and with links to surveys. The script used the prepared tables with information on which of the surveys should be sent to which recipient. The script automatically detected that information and placed it in the body of an email which was automatically sent to a given recipient.

The content of the survey was written in html. Different types of questions were posed in surveys: open questions - where the recipient should type in an answer; closed questions with one or multiple-choice answers, and questions that appeared depending on the answer to the previous question. There were also compulsory questions, which the recipient was obliged to answer. In addition, for fields that were supposed to be answered with a number, an appropriate Java language script was prepared, which warned the respondent about an incorrect answer and did not allow a survey to be sent if it was not answered properly. When all compulsory answers were given and all fields containing numbers were filled in correctly, a message appeared to confirm the completion of the survey and that the data had been saved.

Using a script written in php language, data entered by the respondent was saved to the appropriate text file on the server. Apart from the answers, information on the institution's name, IP address of the computer on which the survey was completed, and on the exact date of its completion were also saved. This data was saved automatically in a form that allows it to be moved in a simple manner into a spreadsheet or directly to a database for further analysis.

The whole concept of the assessment required the creation of about 70 different surveys for different measures and institutions (communes, poviats, voivodeships, ministries, regional water management authorities, voivodeship inspectorates for environmental protection, etc.). In total, over 30000 files were created, because for each institution 
a separate file containing a survey had to be prepared so that the answers of a given institution could be identified.

\section{Summary}

The present and forecast situation concerning reporting in the field of environment protection to the European Commission in the scope of the WFD and other tasks connected with it (the multitude of reports, recipients and supporting documents) leads to the conclusion that the coordination of reporting at the state level and the improvement of the flow of information between the relevant institutions is necessary.

In the opinion of the authors, detailed information concerning the forms and rules of reporting of planned measures should be an integral part of SWEP updates. Those rules should cover not only reporting on measure implementation, but also on the control of these measures. It is necessary to make bodies responsible for the implementation of measures liable for providing information necessary for reporting and thus control the progress of their implementation. The accepted indicators and data must be made known to the bodies responsible for the implementation of measures at the stage of initiating the implementation of further updates of the SWEP.

However, to implement the SWEP successfully, apart from the above mentioned reporting system, effective and multilateral social communication is necessary. At the stage of programme creation, consultations with entities responsible for their future implementation will help to eliminate situations of where there is a lack of awareness of the necessity of the accomplishment of a measure.

The developed concept of a methodology for the assessment of programme implementation answers those needs. The proposed form of electronic surveying can become a foundation for a reporting system of programmes of measures.

Bibliography

Act of Water Law, 2001, The Official Journal of Law (Dziennik Ustaw), No. 115 Item 1229, Act of 18 July 2001 on Water Law, as amended

ATKINS LIMITED, 2011, WFD Reporting on the Progress on the implementation of the Programmes of Measures - A user manual, Version 2.0

CIS, 2009, Common Implementation Strategy (CIS) For the Water Framework Directive (2000/60/EC), Guidance Document No. 20: Guidance document on exemptions to the environmental objectives, Luxembourg, Office for Official Publications of the European Communities
Directive 2008/1/EC of the European Parliament and of the Council of 15 January 2008 concerning integrated pollution prevention and control

Elaboration of analysis of the pressures and impact of anthropogenic pollution presented in the detailed terms of bodies of surface and groundwater for the purpose of the development of programmes and water management plans- ordering party - the Minister of Environment (contract number in IMWM-OKK 442/U/06), 2007, Consortium of Institute of Meteorology and Water Management - the leader, Polish Geological Institute, Institute of Environmental Protection

http://ec.europa.eu/environment/water/water-framework/objectives/implementation_en.htm

The Water Information System for Europe, 2012, http://water. europa.eu/

SWEP, 2010, State Water and Environmental Programme, The National Water Management Authority, Warsaw

Walczykiewicz T., Witczak S., 2005, Rola planów gospodarowania wodami na obszarze dorzecza w strategii ochrony wód podziemnych i powierzchniowych Polski, Konferencja Instrumenty Zarządzania Ochroną Środowiska, Oceny oddziaływania na środowisko na szczeblu krajowym i regionalnym. (The role of water management plans in the basin district in a strategy of protection of groundwaters and surface waters in Poland, 20-22 October, Kraków, Evaluation of impact on the environment at national and regional level), AGH, Uczelniane Wydawnictwa Naukowo-Dydaktyczne, Kraków

Water Framework Directive 2000/60/EC (WFD), Official Journal L 327, 22.12.2000, as amended

Water Framework Directive, 2012, European Commission, Environment, Water

Water management plan for the Dniestr river basin district (M.P. 2011 r. Nr 38 poz. 425)

Water management plan for the Dunaj river basin district (M.P. 2011 r. Nr 51 poz. 560)

Water management plan for the Jaft river basin district (M.P. 2011 r. nr 37 poz. 424)

Water management plan for the Łaba river basin district (M.P. 2011 r. nr 52 poz. 561)

Water management plan for the Niemen river basin district (M.P. 2011 r. $\mathrm{Nr} 58$ poz. 578)

Water management plan for the Odra river basin district (M.P. 2011 r. nr 40 poz. 451)

Water management plan for the Pregoła river basin district (M.P. 2011 r. Nr 55 poz. 566)

Water management plan for the Świeża river basin district (M.P. 2011 r. Nr 59 poz. 923)

Water management plan for the Uker river basin district (M.P. 2011 r. Nr 56 poz. 567)

Water management plan for the Vistula river basin district (M.P. 2011 r. Nr 49 poz. 549) 